\title{
FROM METABIOLOGY TO METAEVOLUTION: A NEW PERSPECTIVE IN (LIFE) SCIENCES
}

\section{Mario Tanga, Giacomo Gelati, Fausto Ghelli}

\section{Corpus (International Group for the Cultural Studies of the Body)}

\begin{abstract}
Metaevolution is the evolution of the potentiality of evolution. This is somehow related to "Creativity" by Chaitin, "Self-production" or autopoiesis by Maturana \&Varela, "Self-organization", to homeorhetic processes, to emergence passages and to the enlarging of the space of status of evolutionary changes.

Metaevolutionary "jumps" in wetware are eukaryotic cell, aerobic metabolism, multi-cellular organization, NS.

Metaevolution can be integrated with exaptation. Crossing over, alternative splicing, epigenetic modifications, transposons and retrotransposons represent the engine of the evolutionary process since they make possible the rearrangement of the metabolic processes and of the anatomo-physiological characteristics depending on the conditions of the external ambient. Metaevolution continues in cognitive-cultural sphere: cognitive transfert represents "noetic exaptation" and metaevolutionary jump. In both cases of Metabiology and of Metaevolution the prefix "Meta-" is useful to distinguish different epistemological levels, even if in a different meaning. A new horizon in Biology: no more dogmas, only the equation: "bio is evo $\&$ evo is bio" (see Dobzhansky), as it is meant also in Evo-Devo Biology.
\end{abstract}

Key words: Metaevolution, Metabiology, Exaptation, Noetic exaptation.

\section{AN OVERALL EXAMINATION OF THE QUESTION}

Metaevolution has been defined in several ways and some authors will be considered in the last part of our paper. We try to re-organize different ideas, proposing our vision about the question.

We start following the line of Gregory Chaitin (Proving Darwin: Making Biology Mathematical, Pantheon, 2012; It. Translation, Darwin alla prova, Dedalo, 2012), that replaces the center of the studies about life beyond biology of organisms. He draws the boundaries of a wider epistemological dominion and includes synthetic informational systems. He replaces bio-centrism with a sort of info-centrism. His position seems to us very interesting and rich of possible developments, even if we do not agree with his "disembodied" vision of life at all.

However, generally agreeing with Chaitin perspective (and with many related Authors and perspectives), we would re-establish the meaning of the term "Metaevolution": it is already used (sometimes too much used or not usefully used...) by many scholars referring to spontaneously evolving systems. We agree with the scholars that define metaevolution as the capability of these systems of evolving their potentiality of evolution. This is somehow related to "Creativity" by Chaitin, "Self-production" or autopoiesis by Maturana \&Varela, "Self-organization" and so on. Besides this is related to homeorhetic processes and to emergence passages.

In other words the result of evolutionary change is not simply the reaching of a different position in the space of status, but [moreover] the enlargement of this space of status (adding a new dimension?...), so that the system can evolve toward positions that before were out of perspective.

The progeny of an organism changes not simply differing somehow from this organism, but moreover increases its range of possible further changes in the future, enlarging the space of status of these changes.

In biology (the traditional one, regarding wet-ware) metaevolutionary "jumps" can be detected, for example, in the eukaryotic cell, in aerobic metabolism, in multi-cellular organization, in NS.

Metaevolutionary jumps do not contrast with the principle of exaptation and can be integrated with it.

Crossing over, alternative splicing, epigenetic modifications, transposons and retrotransposons represent the engine of the evolutionary process since they make possible the rearrangement of the metabolic processes and of the anatomo-physiological characteristics depending on the conditions of the external ambient.

Recent studies have shown that the epigenetic modifications, as a consequence of a new outer stimulus, happen in a very short lapse of time. Moreover it seems that (even though we do not have certain evidences yet) the epigenetic modifications collected by the parents are inherited by the progeny.

Correspondence to:

Mario Tanga,

Corpus (International Group for the Cultural Studies of the Body)- http://corpus.comlu.com

E-mail: m.tanga@tin.it 
These (and others) metaevolutionary knots both separate and link the previous and the next phase. By this reason they give continuity also to the emergence passages from inorganic to biologic world and from this one to the cultural one.

Also cognitive transfert is a meaningful example of both these aspects: "noetic exaptation" and metaevolutionary jump in cognitive-cultural sphere.

In both cases (of Metabiology and of Metaevolution) the prefix "Meta-" is useful to distinguish different epistemological levels, even if in a different meaning:

- In Biological Sciences it allows to define the more extended and general class of living beings, including those that do not belong to wet-ware-systems.

- In Evolutionary Sciences it allows to distinguish the different quality of the phases of evolutionary drift: the "normal" ones (when transformations are cumulated ) and "metaevolutionary" (when suddenly and unexpectedly further spaces of status are "created").

A new age for biological sciences: $\mathrm{BIO} \leftrightarrow \mathrm{EVO}$ is the new focus, as a central equation.

No more dogmas in Biology, only this equation: "bio is evo $\theta$ evo is bio". Besides maybe it is falsifiable, in Popper's sense. But in the meantime we can keep it as the central focal point in Biological Sciences. (Re)defining life, understanding its nature, knowing its properties and possibilities. It is a philosophical, ethic, biological and operating problem. A complex and deep problem. We cannot define as "alive" or "living" a system since it is born, grows, nourishes itself, procreates and dies. Many, too many inanimate things do this, even very well. Something is alive if it evolves. If something evolves it is alive or we can consider it so.

\section{POETRY AND SCIENCE TALE THE SAME (HI)STORY...}

Caminante son tus huellas

el camino y nada más;

caminante, no hay camino

se hace camino al andar.

$\mathrm{Al}$ andar se hace camino

y al volver la vista atrás

se ve la senda que nunca

se ha de volver a pisar.

Caminante no hay camino

sino estelas en la mar...

Antonio Machado, "Proverbios y cantares" in Campos de Castilla, 1912

Wanderer, your footsteps are the road, and nothing more; wanderer, there is no road, the road is made by walking. By walking one makes the road, and upon glancing behind one sees the path

that never will be trod again.

Wanderer, there is no road

Only wakes upon the sea.

Even if maybe Machado did not refer to this, in this poem, he grasps the essence of evolution, that is to say the essence of life. Artistic intuition of a poet or conscious methaphor? It has no importance. It is useful to explain and to understand evolution.

"Todo pasa", "Panta rei": Eraclitus docet... world is fragile, life is fragile, things change easily, we must accept this variability, we must love it, it is the unique world we have, and the poet loves it, even if it is "como pompas de jabón", as soap balls...

No living being, no life form is aethernal: death, extintion are the unavoidable rule, we can see them "temblar/ súbitamente y quebrarse".

"Caminante son tus huellas/ el camino y nada más;/ caminante, no hay camino/ se hace camino al andar./ Al andar se hace camino/ y al volver la vista atrás se ve la senda que nunca/ se ha de volver a pisar": the (hi)story of life is not a rigorously structured plan: only after we can try to individuate its strange, complicate line. It is no possible to find a logic (neither of "progress" nor of different kind...), a continuity in history of life, it goes on, however, but random is a very important aspect of its main way of going: “¿Para quél lamar caminos/ los surcos del azar?..." And, without random, no plasticity, no adaptament would be possible.

History of life is not a linear logic progress aimed at a final target, it is not a growing, but nevertheless it is not reversable, past is past, it will never come back: "Al andar se hace el camino, y al volver la vista atrás/ se ve la senda que nunca/ se ha de volver a pisar".

The traces of life are not engraved on solid rock, the land is fluid, it makes the traces flow away easily, it is overcome by new forms quickly: "Caminante no hay camino/ sino estelas en la mar...".

There is no smooth continuity: a step between a balance point and the next one is a sudden jump. As in pointed balances model, steps are marked, as along the path of the poem, by sea stars: "Caminante no hay camino/ si no estelas en la mar". We do not know the moment, the distance and the direction of these steps until life has done them...

\section{FRAMING THE QUESTION}

Gregory Chaitin speaks about "Metabiology": the Science of Life Beyond Livings. Information evolves, therefore it (synthetic software as much as biological organisms) is alive. Disregarding its implementations, information evolves. This involves an extension of the semantic field of "life".

Analogously we can speak about "Metaevolution" 
according to a particular meaning among the used ones: we do not speak simply about the only evolution of structures and functions of wet-ware and soft-ware, but, more extensively, about the transformations of the space of status of evolutionary possibilities. It is linked to information and self-organized information. Chaitin speaks about evolutionary information as a "creative" system. This remembers to us self-production and homeorhesis of H. Maturana e F. Varela.

But we must consider evolutionary systems over the faculty of changing themselves: information has the power to enlarge even its own dominion of potential changings. Evolution does not simply happen: it is a multiplanar process. It is not a summative process: there are critical points of "explosive" transcendent passages.

In order to understand this it is necessary to replace bio-centrism with info-centrism.

Biologic beings and biological evolution become a particular sector of a wider scientific-ontological field.

Different kinds of information are related one another, building an intricate network capable of grasping the enlarging of the field of possible evolution. It is not a linear chain with only feed-forward and feedback causations. This draws a continuity among these different kinds of information that implement metaevolution, that is to say evolution of evolvability.

Many kinds of information (genomic, of chemical mediators, nervous, noetic, of synthetic soft-ware ... and tomorrow?...) have progressively drew the road of evolution and metaevolution.

Before there was no road, nor land for the road.

Information is the "caminante" (the wanderer) by Machado: it drew, draws and will draw its road and its land, always by going and going...

It does not follow a straight line, does not explore a previously seen land: it maintains its dialogue with world and its dialectic relation with world open.

It makes itself more and more ready and capable of changing, of creating new roads and new lands...

According to Gregory Chaitin, we think that it is necessary to replace the center of the studies about life beyond biology of organisms. He draws the boundaries of an epistemological dominion that is wider and includes synthetic informational systems.

According to this we would re-establish the meaning of the term "Metaevolution", that is not new: it is already used (sometime too much used or not usefully used...) by many scholars regarding referring to spontaneously evolving systems. Metaevolution would be the capability of these systems of evolving their potentiality of evolution. This is somehow related to "Creativity" by Chaitin, "self-production" autopoiesis by Maturana \& Varela, "self-organization" and so on.

In other words the result of evolutionary change is not simply the reaching of a different position in the space of status, but moreover the enlargement of this space of status (adding a new dimension?...), so the system can evolve toward positions that before were out of perspective.

Along the generational line of an organism we can notice that this organism changes not simply, but moreover its range of possible further changes for the future.

In biology (the traditional one, regarding wet-ware) metaevolutionary "jumps" can be detected, for example:

- in the eukaryotic cell

- in aerobic metabolism

- in multi-cellular organization

- in NS

That is to say, referring to one of the previous examples, an anaerobic cell can evolve in many different ways. If it acquires oxidative metabolism, by endosymbiosis or by any other way, it obtains a much higher energetic efficiency. This allows it many evolutionary possibilities, that are not existing without the new metabolic mechanism.

For these reasons the jump toward aerobic metabolism is not simply evolutionary (giving a different -in the evolutionary meaning- cell), but also metaevolutionary, because this novelty opens a landscape of new possibilities.

In an analogous way, multi-cellular organisms have obtained many new perspectives, at least to reach a wider range of dimensions: from very small (the unique possible for the unicellular organisms) to enormous (a whale, a dinosaur, a sequoia...). Besides, with many cells available, a differentiation of tissues and of the structure becomes possible.

\section{WE SHOULD BEGIN (RE)DEFINING LIFE...}

Life is the property of a system that is capable of maintaining and further lowering actively a low level of its own entropy (a high level of order), disregarding the entropic gradient between itself and the external world.

Contextual factors cannot be disregarded in the economy of the living being, but it has the possibility of avoiding the submission to deterministic connections and to the strength of these factors.

Separation between itself and the environment is an important condition that allows a system to be alive. This separation should not be necessarily a material barrier. In "cell-free" systems cell barrier is erased, but nevertheless they can be defined alive (they have, maintain/increase and manage low entropy by metabolic activity) since the system however has the opportunity to keep its own processes distinct from the environmental ones, similarly to the presence of a real separation.

Due to this the living being can be considered an active pusher of entropy in centrifugal direction: a dissipative system as meant by Prigogine.

This is implemented by the self-organization of the system and by the informational systems that are part of 
it (DNA, RNA, chemical mediators, enzymes, and, if they are present, N.S. and immunity systems). These informational systems are hierarchical, reticular, dynamic and have several levels of organization and functioning.

This information has self-causative properties and acts on organisms and on world. So it directs relations with environment finalizing them to coordination and self-maintaining (that is to say persistence of some invariants), to restoration (erasing the effect of perturbing factors thanks to reversibility of certain processes), to compensation (balancing perturbing factors by opposite effects of other factors), to expansion (trend of increasing existential dominion) of living being, but first of all of itself, in Dawkins' opinion, as he explains in The Selfish Gene.

The self-organization persists thanks to the fact that the living being is characterized by a condition referable to deterministic chaos.

We can classify systems as:

- simple (with a low number of variable factors, usually until four, as it happens in classic mechanics)

- characterized by not organized complexity (many variable factors do not have or have a very few relations one another, mainly studied by statistics)

- characterized by organized complexity (many variable factors and a dense network of reciprocal relations).

Even if it seems a paradox, the last ones are capable of maintaining themselves apparently static thanks to the fact that they are crossed by highly dynamic fluxes of different nature: matter, energy, information.

Each of these resources flows through the living system, and a double flux is always active, from external side toward internal one and vice-versa. These two fluxes are related one another and are reciprocally regulated to ensure the maintaining of a condition that is compatible with life itself. A low (very low) level of entropy is the attractor of the balance of this double flux, or it is something capable of causing a further lowering by positive feedbacks and homeorhetic processes. The balance between input and output is continuously engaged in a systemic way: if we act on one of these two fluxes, we act on both of them. This balance is not static. It is and is maintained far from the entropic trend. Besides it can be further pushed in a direction that is the contrary of the entropic trend: the symmetry between the two fluxes can be modified in a sudden and conspicuous way. Even a small cause, if meaningful, can originate a non-linear consequence, by a self-magnifying process, a positive feedback. So we can have (or not have, according to the trend of the famous balance) a persistence, a development or an alteration of functionality/morphology (at the ontologenetical level), evolution or the maintenance of the characteristics of the species (at the phylogenic level)...

In order to maintain/magnify the entropic gradient between the two sides of the compartmental barrier or of the limit between itself and the word, the living being uses external sources. That is to say that its (internal) low level of entropy is gained and kept thanks to an external increasing. The internal lowering of entropy is less conspicuous than the external increasing. In other words the whole trend of total entropy of the living being and of the environment (external and internal together) respects the Second Principle.

We must consider a very important detail: in the set of possible conditions of the system (living being + environment) this distribution of entropy has a very low probability. Nevertheless life exists and it originated from not living systems...

To be born, to grow, to reproduce, to metabolize, all these activities are not characterizing life, but are referable to this property (or set of related properties): to manage the entropy. And this property is to the central element of life: information. When we speak about "life information" we mean an information that is entangled in semiotic processes, that is to say computation, self-organization referable and communication all together. Communication links both information and metabolism (soma), both organism and world.

Life (information) is a complex, chaotic, self-organizing, evolving system. Thanks to this it is not static, life properties can emerge not only in "wet-ware". Besides it needs interaction processes.

This conception of life makes it something different and more general than the traditional vision. Besides, this definition makes us extend the dominion of systems that are definable "alive": not only wet-ware-systems, but also informational ones: Biology becomes Metabiology, Evolutionism becomes Metaevolutionism.

\section{TOWARD THE CORE OF THE QUESTION}

Trying to focus the "status of the art" in biologic sciences may be opportune. It is due to the fact that these sciences have gone very far, overall since the $\mathrm{XX}$ century. In this great transformations the implication of many different disciplines (even not strictly biologic or quietly extraneous ones) is included.

Conceptual dimension of Life Sciences has become more and more deep and extended and has dropped out from the disciplinary pool toward a meta-and trans-disciplinary horizon.

First we must have acquaintance with the main turning point of biology that has to be reconsidered in an evolutionary key. This is clearer and clearer.

In traditional biological sciences phylogenetic history was an optional tale, added to the description of their structures and functions, but now it has become fundamental to define them, but without separating them from phylogenies.

Phylogenies, ontogenesis, physiology, reproduction are related one another by links that are more intricate. Recapitulation Law by Haeckel was an interesting 
idea, but now it is no more effective to explain the nature of life. Among the most meaningful turning points of contemporaneous life sciences there is the Evo-Devo Biology.

Evolution is becoming the central paradigm of contents and methods for studying and understanding living beings (on every dimensional and complexity scale, from molecules to ecosystem) and even the life itself (as the distinguishing set of properties of these beings or systems).

About so wide and deep themes more and more numerous and different disciplines are connecting one another. Evolution is no more matter for the evolutionary biologists only.

All biologic sciences cannot eliminate the base of evolutionism, but the dominion of the evolutionary processes is much wider. In other words: at the beginning evolution was part of life, but now life is part of evolution. That is to say: life, but not only life, evolves.

Some time ago Dawkins introduced "Memes" in the landscape of (bio)semiotics and established an autonomous study: the "Memetics". This somehow resembles to "writing myth" by Plato. He looked at writing with no confidence, since it becomes autonomous from its author.

We can find the importance of informational aspect also in information science, in actual chemistry (see Prigogine) or in Physics (see Enzo Tiezzi).

In particular about Physics, we have to notice that information (that is always connected to evolution) was introduced with qubit and with quantistic paradigm and it has acquired more and more importance.

But curiously the radial explosion of extremely specialized sciences contrasts with vigorous convergences and dense networks of relations that are becoming more and more real. That is to say that we find intersections of contents, exchange of methods, contamination of languages.

In the history of science and of sciences, when some important change happens, we need time after these events to have a right and clear vision of facts and to judge them. Only in this way we can have the necessary objectivity.

We can start from two different sources. First we have to consider the New Evolutionary Synthesis (in its original version of ' $30 \mathrm{~s}$ and ' 40 s of XX century and in the successive extended version, however including genetics as fundamental part). After we must consider Math, information Science, Informatics (always starting from Thirties of XX Century with Gödel, von Neumann, Turing and so on).

These networks of relations (that involve several disciplines) have demonstrated that, never as in (late) XX Century, any theory can be an isolated independent system, owned by a unique science.

Always internal and external transformations correspond one another. Mathematical sciences, for example, draw a meaningful passage from number to compute, from the perfection of the structure to the dynamism of the transformation, from contemplation to action. Similarly to Neurosciences, in which the focus is moved from neuron to synapse, in Maths something analogous happens: this science becomes less "ontological" and more "algorithmic".

Information is no more statically "deposed" in symbol, it must be aroused by computation, that is the new paradigm of its genesis. Analysis and synthesis, as meant by Kant, are far in the past.

The processing becomes the central condition and it is connatural to information. These two things involve one another. The computing-transformation becomes autonomous from computing subject, goes on motu proprio, a black box in which the subject looks a posteriori, to see what is happened and how.

Computing becomes autonomous from the subject and this makes us think to Plato's suspects about writing or, jumping 25 centuries after, to Dawkin's "memes".

Creator becomes spectator. He looks at information (that he has created) as something autonomously acting.

\section{PERSISTENCE AND PLASTICITY AS DOUBLE REGULATORS OF LIFE HISTORY}

Watching it operating, he grasps two fundamental decisive features, dialectically combining one another. They are: "Persistence" (capability of balancing perturbations and interferences by homeostatic processes) and fluency (capability of changing, exploring the space of status of possible variations, a sort of creativity, as it is called by Chaitin), that we can call "Plasticity".

\section{Persistence}

Persistence is implemented by homeostasis and by retention devices of information, by stabilizing mechanisms, by negative feedbacks, by active barriers protecting information. DNA has enzymes that correct errors in genomic duplication, neurological memory has a tolerance for missing or incoherent information, pattern of nervous impulses, identity of chemical mediators, etc. against perturbing factors, by reconstructing eventually destroyed or altered parts. All these devices act repelling/neutralizing whatever menaces the status quo.

Biological structures have the capacity of retaining information with a certain warranty of maintaining it constant during time. We find many examples of persistence of innate and of acquired features. The acquisition may be of different nature and after different processes: epigenetic, of learning (by modification of micro-architecture of nervous connectivity), of immunity (organizing defence against antigenic factors). But even the persistence is not the product of the passive and static deposit of "something abandoned somewhere without disturbing it". It is sustained by active 
mechanisms, capable of considering internal and environment factors.

Also structures and mechanisms that balance perturbing action and that reactivate the original condition of information have a preserving function, so information capable to persist acts like an attractor. All these processes can be seen as a biological memory, an extended meaning if compared with the strictly neurocognitive one.

We can indicate also homeostatic and/or stabilization mechanism, that are related one another, but do not coincide.

\section{Plasticity}

Plasticity allows the outbreaks of spaces of status where we can find variations of original information and it allows the exploration of this space of status. Genome is subject to mutations that are due both to random fluctuation and to interaction with environment that is capable to activate epigenetic dynamics.

And besides the recursive nature of NS allows vary contents and messages in an autopoietic way.

These can integrate themselves together or can change, by interacting with external factors. This space of status opens up, thanks to the fact that persistence mechanisms allow non-deterministic margins.

Here we find disorder, but it is a non-entropic one. It allows self-organizing dynamics appear.

This is one of the most meaningful news in the evolutionary landscape: not simply the random varying of not organized complexity that is given by mutations (a casual exploration of the space of status, similarly to a particle that is subject to thermal agitation and occupies different positions in adjacent space), but the elective directing toward attractors, even of strange location in the space of status. Nevertheless these attractors are sufficient to restrict the spectrum of variations and to push the evolutionary process in a quicker way, even if they do not constrict the process in a deterministic way. However this does not request direct interventions of a supernatural Being or the actualization of his Intelligent Design. The Second Principle is not contradicted!

Moreover it is framed in a wider and more inclusive context. As Prigogine showed, systems that are already far from balance follow a trend of further increasing of this distance. This self-organization "strength" pushes the system evolution toward certain directions instead toward other ones and, due to stronger reasons, prevents absolute hypostasis. The self-organizing capability of the system can be considered as creativity and emerges in the interaction between subject and environment. Living beings (from a single cell to a population of organisms or to the whole ecosystem) are complex and for this reason they have the feature of chaos, of self-organization (but never of a rigid or closed order) that is regulated by one or more attractors, of the dialectic between persistence of its "status $q u o^{\prime \prime}$, (even far from thermodynamic balance) and its opening to change. In the space of status of possible changes, attractors occupy strange locations. So the space of status is anisotropic (on the contrary of the neutral and indifferent casualty, where each possible configuration is equivalent to each other, except for the entropy trend) and plays with entropy so it makes not only possible but even more probable such elective configurations. It is unavoidable to refer to Maynard Smith's canalization. Environmental factors are decisive and act through subtle and complex mechanisms. According to Maynard Smith, we must remember that environment-organism incongruity is temporary, even if it exists. During environmental changes, fitness grows and bridges the gap. Only during one of these periods and only regarding certain aspects we can speak about "progress". Plasticity is closely referable to homeorhetic and self-organizing processes.

If a system has an informational content beyond a quality/quantity limit and if it is far enough from balance (as meant by Prigogine), it evolves toward a condition that allows it more and more quickly.

In this evolution we notice emergence conversions and the consequential gaps of dominion. In life's history we can detect some gaps of these. Metaevolutionary knots that mark these passages can be identified in some events.

- DNA

- Prokaryotic-eukaryotic cell

- Endosymbiosis (mitochondrial inclusion for oxidative processes and energetic production)

- Multicellular (from cell colonies to tissues in complex organisms)

- Epigenesis

- Hormones

- Synapses junction and NS (adaptation, learning)

- MIND (abstract thought, abstract learning, cognitive transfert, intuition, feed-forward, etc.)

- Synthetic software

Similarly to every emergence transition, we have circular cause-effect between original and emerged system that links one another these dominions. See also the conception of Metaevolution in Paras Copra, described after.

The attractor of these evolutionary processes is a wider and wider space of status of possible configurations.

In other words evolution is self-referred.

\section{Self-organization}

Self-organization is relatable to plasticity. It is a property of complex systems, thanks to which a particular order emerges. These orders are ruled by different attractors.

Self-organization generates and feeds system information, developing its potentialities, that are not predictable by linear and deterministic models.

Without self-organization, erosion or wasting of information would be unavoidable. Information would be submitted to entropic rules. 
Traditional lore acknowledged spontaneous generation of living beings starting from inert matter. Nevertheless these beings could not generate a progeny that overcome them in scala naturae...

Strange intersections between Galilean determinism and epigenetic theories (in the preformistic meaning) that emerged after the scientific revolution, originate the result of impossibility of evolutionary changes for living species. This happens because each generation is forced to repeat the previous one and so it will generate a future one that will be identical. A rigid paradigm of rigidly fixed species, where only a few exceptions can find space, but these are monsters without evolutionary meaning.

Complexity paradigm gives a wide space to self-organization. We see it in each life process, both phylogenetic and ontogenetic. Besides, these processes cross one another as we see in Evo-Devo biology.

A recent experiment enforces this vision. Michael Doebeli and Mattew Herron, of the University of British Columbia, have been growing three population of Escherichia coli for six months. During this period they had one thousand generations. These three populations have been exposed to same conditions and each of them has been fed by two different solutions: one with sugar and one with vinegar. Each population had the same evolution with the same result: it is divided into two under-populations, each one specialized to feed by one of the two solutions. Obviously the fact that we observe the same process in all the three cases allows us to say it is not a random process. This research have been published in "PloS Biology" and we can read about it in "Le Scienze" n. 536 of April 2013.

The model of evolution made by Maths tries to show the qualitative aspects by quantitative factors. It is not a new form of reductionism, due to the fact that now we consider complexity, transformational dynamics and interaction networks.

The "Vis Evolutiva" (that implies variability, selection and-this is the novelty-self-organization) is the distinguishing feature of life. This is related to the fact that the last irreducible element of living being is information.

Dobzhansky is right when he inscribes the whole universe of biologic sciences within the horizon of evolution. Genome can be meant both as individual equipment and as genetic pool of a population, as the pangenomic approach indicated as very important heuristic method. In both cases it is the result and the driving force of onto/phylogenetic history.

It is unavoidable that to detect biological phenomena means to make a sort of archaeology of the software of the life, as clearly was showed by Chaitin.

Information (to be properly called so) should have properties that emerge from the system that implements it, even not necessarily in a deterministic way.

Information is self-organized and it can be "antientropic". Chaitin attributes creativity to it, meant as an intrinsic capability of originating evolutionary processes or, however, of transforming, regaining and linking to the concept of evolution creatrice by Bergson (1907), of devenir by Deleuze, of vital force by B. Shaw (see the third act's dream sequence of Man and Superman of 1903, more exactly referring to Don Juan in Hell).

In the organism the first information carrier is DNA. As last but not least confirmation of this fact, in "Le Scienze" of March 2013, we find the announcement of an Hard Disk that, using exactly DNA as material, obtains an information compression that has no precedents.

Gregory Chaitin reaches extreme consequences of this heuristic turn. Considering the landscape of the $\mathrm{Bi}$ ology of the second half of Twentieth Century, this turn is not fully unexpected.

If we accept the premise that something can be fully understood only if it is re-created, Chaitin shifts (this is the novelty) the nature of this "re-creating". Even in a scientific perspective, different from the mythologies regarding Frankenstein or Paracelsus' homunculus alchemicus, in 1953 the Miller experiment proposes again the enterprise of recreating life. One time more it was meant as wet-ware, coinciding with the conception of life until that moment. Chaitin thinks that scholars can and must disregard the equivalence life $\leftrightarrow$ wet-ware, since it is not defining life itself. Wet-ware implementation of life can be transcended and scientists can propose a "disembodied" version.

If we reduce life to minimal terms, Chaitin says, to its not further reducible element, to the only "conditio" that makes it so, life is information, or, more exactly, life is information that is capable of evolving. Metabolism away, sex away, plurality away (plurality of individuals in a population, of species in an ecosystem...), body away (we can say "soma"), the remaining thing is the bare software, even still definable functioning and living!... So biological "prometheism" shifts in soft-ware creation. "Bio" and "Bit" have a somehow equal functioning [cf. Tanga, Ghelli, Darwin between Bio and Bit, JSAS), they are confusable one another!... This is called "Metabiology" by Chaitin. Its main subject is life disregarding wet-ware.

This approach has the great value of creating a Math that is biologic itself (biologic in a deep sense), not simply a mathematical model of life!

No more a "model of-", a simulation, but life that is homogeneous to (biological) life, mutatis mutandis, obviously. We do not still know very well where this road will lead us, but the developments will surely be fertile and charming. Nevertheless we must be awareness about implications and risks.

The first (theoretical, but also heuristic and applicative) risk is a neo-functionalism, due to equal functionality (of material implementations and of biological -of wet-ware- processes), makes life free from contingences, isolates it, erases its immersion in the environmental networks. All these factors would establish reciprocal belonging between living being 
and environment. In our opinion, the isolated condition makes us misunderstand life's nature, wastes its sense, even erases it.

The "conditio" for the interaction life-environment is the material implementation of life itself. The co-extension subject-environment and the semiotic/causative exchanges happen in the material dimension. It is not an empty terminological question about difference between bio-semiotic and bio-information. The first one includes real communication processes, the second one is referred only to abstract contents, disregarding concrete interaction.

We think it is necessary to adopt the first perspective and to look at researches, visions, models that are centred in the interactivity, meant in the strongest acceptation. Saying this, overall we refer to recent developments in sciences and philosophy. More exactly we refer to complexity science, to networks science, to theory of EEC, of IIB, to externalism, and to specific models as the one of epigenetic processes, of neuronal Darwinism, of clonal selection of hypercycles by Kaufmann. In particular this model clearly shows as enzymes -that is to say proteins, or, in other words, phenotype- and genome are indissolubly included in the same functional unit; at least, we must learn that the -causative and chronological- priority question between DNA and proteins may be a false problem.

These are fully biological examples of how and how much the biological software cannot be disembodied without consequences.

And in 2013 the Nobel in Medicine honours the research on cell communication...

However this indicates that caution is necessary.

The second risk is a re-proposal of Neo-Platonism, due to the fact that to make oneself free from materiality seems to lead us to purity and to freedom of the most authentic information. Virtual space where programs "function" (that is to say: "live and evolve") seems a sort of hyperuranium that transcends material world, where entities (poor copies that implement hyperuranic ideas) are burdened by their weight, by their material thickness and opacity.

Phenotype obstacles and limits information of which at the moment it is bearer, but the limits of phenotype can be transcended by the hereditary transmission.

It is unavoidable to refer this to Dawkins, cited by Chaitin: "What are my organisms? Well, in his book The Selfish Gene, Richard Dawkins teaches us that bodies are unimportant, they are just vehicles for their genes. So I throw away the body and just keep the DNA."

Surely this inversion of perspective is provocative but it has a positive role, but, as we said, it is not without risks.

It is necessary to run quickly to remain in the same place. This implies to come back from Parmenides to Heraclitus. This is the passage from homeostasis to homeorhesis. The static nature of hypostasis, of the maintenance, of the "status quo" is illusory. Rather it is the result of a complex of dynamics reaching a not very probable balance.

Darwin was conscious that his theory was so good to be extended to wider fields, even if he could not imagine it will become referable to what he did not know yet: synthetic software...

So we can dissolve the previous boundary between life and not-life, alive and not-alive and even the limit between organic and inorganic. Now we must consider a new distinction as preeminent: the one between evolutionary and not-evolutionary systems. Biologic and synthetic systems, as much as certain software, are placed on the first side of this distinction.

Evolution is a property of particular systems that, thanks to this, are placed in a special relation with entropy and with the Second Principle.

Evolution is not simple changing, or actuating of preexistent, pre-structured potentialities, but it is creation of new potentialities.

As we said before, Life is information that is capable of evolving.

Evolution slowly (but there are no fixed times) changes a species, changes all species (during the reiteration of generations along the line of descent) and their relations, but it is also the transformational drift of a single individual, disregarding the consequences on hereditary transmission.

Evolution is always dialoging with external factors. Embedding in environment (and networks of relations with it) causes the reciprocal belonging of subject and environment. This factor is inescapable for evolutionary dynamics, both ontogenetic and phylogenetic ones.

Each system (physical, biological and noetic ones, so called in the classic taxonomy) owns informational content.

This informational content has features that allow to place it in one of two poles, respectively definable "evolvability" and "not-evolvability".

Not-evolvable systems statically and conservatively maintain information. Nevertheless during flow of time it can be subject to erosion. This fact makes information take a residual feature if compared to previous condition.

On the contrary, evolutionary systems manage, transform and (if necessary and if permitted by conditions) increase informational content.

The "Vis Evolutiva" of evolutionary systems (that implied a three-fold order of factors variability, selection and -this is the most meaningful novelty, comparing present evolutionism to Darwin's original theory- selforganization) is the distinguishing feature of life. This is related to the fact that the last irreducible element of the living being is information.

Dobzhansky is right when he inscribes the whole universe of biologic sciences within the horizon of evolution. Genome can be meant as individual equipment and as the whole genetic pool of a population (as pangenomic vision suggest). This two perspectives are 
very different, but in both cases it is the result and the driving force of an ontogenetic/phylogenetic history.

It is unavoidable that to detect biological phenomena means to make a sort of archaeology of the software of the life.

Information is everything capable of reducing the field of possibilities. Applying or using information we can make smaller the space of possibilities. The "indetermination" is decreased in variety and/or number of possible cases among the ones that can descend from early conditions. Information leads, pushes or canalizes self- and other- referred processes, even if this action is not necessarily deterministic. A margin of open possibilities is left, but the direction of transformation processes is pointed.

This is a general definition, but the bio-information increases the margin of possibilities. It seems to contradict the principle of progressive irreversible specialization that is the constant direction of evolution. Nevertheless it is possible thanks to the fact that evolution produces more plastic and open systems. A more refined organism has more freedom of choosing. This is a limit only if environment changes beyond critical limits until it makes the organism's plasticity not useful. If it happens, conquered targets become a limit. However evolutionary information avoids absolutely fixed contents. Variation devices are allowed or searched.

Evolution flow can be considered an homeorhetic multiplanar process that self-rises by creating the conditions to develop a wider range of possibilities, that is to say a wider dominion for further changings.

We clearly know that the creation of this conditions cannot be planned before, that there are no previous aims, but we can think that life takes advantage from the new situation and it uses these possibilities in all possible directions to grasp adaptive advantages.

A change makes further and wider changings possible. Changing arises changing. It acts a positive feedback that makes Chaitin speak about creativity, that remembers to us homeorhetic or self-organizing processes.

During history of life we can focus some decisive moments when this opening of opportunities becomes particularly evident, as just we have said.

\section{THE CASE OF EXAPTATION}

A fundamental strategy of evolution is the exaptation. It allows to overcome handicaps of adaptation, to solve the lacking of something. Rearranging something existing the play is done... Exaptation was described by S. J. Gould and E. S. Vrba and allows us to notice that evolution is not a series of creations "ex nihilo": too much difficult, too much time, too much resources. Maybe it is better (and several times it is really better!...) to use something already existing, disregarding if its actual use is fully different from the newly requested one. A few somatic/genetic changes and the new need is satisfied. Perhaps the adapted (it is more proper to say "exapted") structure is not optimal, but very probably it can obtain its aim with effectiveness. And it is enough.

These dynamics seem to suggest that evolution works according to saving energies, matter and information, similarly to shorten its range of action. This is a real principle of evolution and it was genially discovered by S. J. Gould and E. S. Vrba. We only say that it must be placed in a dialectic relation with the complementary principle of meta-evolutionary jumps. No reciprocal exclusion: simply reciprocal integration. This synergy can be observed in the cases of coinciding of exaptation and meta-evolution. A meaningful example: lungs of terrestrial vertebrates derive from swim bladder of ancient fishes by exaptation. Nevertheless this allows a meta-evolutionary jump: expansion of ecological dominion, no more reliance on water to breath, new opportunity of feeding, of developing new motor structures and functionalities, and so on...

Genial rearranging and saving of exaptation by S. J. Gould and E. S. Vrba does not eliminate the great creative strength of evolution by Chaitin!... These are the different sides of the same wonderful history.

\section{THE CASE OF RETROTRANSPOSOSNS AND EPIGENETICS}

Evolutionary "jumps" and metaevolutionary knots are the result of an extraordinary ability to adapt, made possible by biomolecular mechanisms such as crossing over, alternative splicing, epigenetic modifications, transposons and retrotransposons.

Retrotransposons represent roughly half of the nucleotides of human genome and they come from the archaic molecular systems capable of replication that invaded eukaryotic genomes hundreds of millions of years ago. In 1988 Haig H. Kazazian Jr. and his brain trust, demonstrating the existence of active retrotransposons in human tissues, reevaluated the so called "rubbish DNA", previously considered without function.

A particular retrotransposon called Ll -Long Interspersed Element 1- is very able to spread its copies in the genome and it seems to have a fundamental role in human beings.

Until recently most part of the scientific world believed that Ll retrotransposition happened mainly in germline and in embryo, after all there were few clues of active Ll in somatic tissues. Moreover -according to a version of the theory of evolution- since genes exist only in order to spread themselves, active retrotransposons in somatic cells were considered quite useless, since these cells are not capable of passing on the DNA to the progeny. 
On the contrary, thanks to technological progress, now we know that retrotransposons are active after the embryonic development in somatic tissues too, in particular in NS.

Fred H. Gage (Salk Institute for Biological Studies, La Jolla, California) and Alysson R. Muotri (University of California, San Diego) have observed the strong activity of Ll in human brain and they recently have made several experiments in order to describe the phenomenon in more detail.

Highlighting cells with a new Ll insertion through fluorescence, they observed that in mice, after physical activity, after the exposure to a new outer stimulus and, in general, to difficulties (factors that stimulate the neurogenesis), the number of marked cells in hippocampus was doubled.

So the Ll activity increases with the learning and with the need of adapting to new situations.

Moreover, thanks to a recent discovery, we know that the lineage of retrotransposons $\mathrm{Ll}$ active in human genome evolved roughly 2.7 millions of years ago, after the separation of the evolutionary lineages of humans and of chimpanzees. This observation confirms somehow that Ll elements are at the basis of the very quick ability to adapt of our brain and that probably they have been fundamental in Homo Sapiens evolution.

Now we focus on a fundamental biomolecular regulation mechanism of gene activity: epigenetic modifications. Recent studies have shown that the epigenetic modifications, as a consequence of a new outer stimulus, happen in a very short lapse of time. Moreover it seems that (even though we do not have certain evidences yet) the changes collected by the parents are inherited by the progeny.

Eric J. Nestler (Friedman Brain Institute, Mount Sinai Medical Center - New York) and his colleagues are finding evidences of the fact that epigenetic modifications can influence brain reaction to new situations and the behaviour too. In particular their researches focus on the effects of chronic stress and drugs.

Sometimes the epigenetic modifications last for a short lapse of time, in order to make the nervous cells answer quickly to a strong stimulation producing a prolonged releasing wave of a neurotransmitter. Other times the changes last for months, for years, or for the entire life too influencing deeply the physiological functions. These mechanisms are fundamental for the ability to adapt and so very useful, however Eric J. Nestler has observed that they can fail in diseases such as depression or addiction. He has studied on mice the epigenetic modifications that modify the activity of brain reward centres genes as a consequence of cocaine use (since this drug can cause addiction in animals too) and he has observed that a single drug dose causes significant and widespread changes in gene expression: one hour after the first cocaine injection about 100 genes are activated for the first time. When the cocaine use becomes chronic a smaller part of these genes is si- lenced, whereas a bigger part becomes much more active. Furthermore some of the epigenetic modifications on the brain reward centres genes, caused by the daily drug use, last for very long periods of time, even after the complete interruption of cocaine injections. This mechanisms are at the base of addiction, since they predispose the genes to future reactivations.

Eric J. Nestler and his brain trust have discovered that chronic drug use increases the activity of some genes inhibiting histone deacetylase and methyltransferase: more acetylated or less methylated chromatin is expanded, so genetic transcription can take place. Coherently they observed that even the inhibition of these two enzymes lasts for a good deal of time.

Eric J. Nestler's laboratory has made also studies on depression making docile and aggressive mice live together. Ten days after the beginning of the cohabitation docile mice were not able to enjoy any kind of pleasure, they were shy, anxious. Some of them became obese since they had found consolation in food. The brain trust has observed epigenetic modifications in about 2000 genes of brain reward centre; in particular in about 1200 genes the histone methylation (inhibition of gene activity) was particularly increased. So it seems that depression can silence the genes capable of activating the brain reward centre, creating a sort of "molecular scar". The same epigenetic changes have been found even in human brain samples taken from people suffering from depression. Treating the mice with an antidepressant such as imipramine the modifications could be reversed.

However a part of the mice were resilient to depression and many of the epigenetic modifications caused by the stress were absent. On the other hand the brain trust detected a new different epigenetic change on a group of genes in brain reward centre. Probably at the basis of resilience there is an alternative pattern of modifications playing actively a protective role against the stress effects. Moreover Eric J. Nestler and his colleagues discovered that the protective genes showing the particular pattern of epigenetic changes in resilient mice are the same genes whose correct activity, in mice suffering from depression, is restored by imipramine. Most part of these genes enhances the activity of brain reward centre and so they act as a shield against depression. So, probably, antidepressants activate protective epigenetic patterns that are already working in resilient subjects.

Michael Meaney and his brain trust (McGill University, Montreal) demonstrated that epigenetic modifications can influence the behaviour all life long too. Meaney's team has studied the effects of maternal cares on epigenetic modifications and the resulting progeny's reaction. They observed that the effects of maternal behaviour partially depend on epigenetic mechanisms. The babies raised by negligent mothers have a much higher DNA methylation grade in the regulatory sequences of the gene for the glucocorticoid receptor 
(which mediates the organism's response to cortisol -the stress hormone-) than the babies raised by caring mothers. This methylation, observed in the hippocampus, makes the nervous cells produce a minor quantity of receptor. In mice, the decrease of the receptors due to epigenetic modifications, caused anxiety, insecurety and, in general, a worse response to stress, since the glucocorticoid receptor activation in hippocampus makes cortisol production decrease. Moreover these changes on babies' character last for the entire life.

However DNA methylation grade in the regulatory sequences of the gene for the glucocorticoid receptor is not the only cuause of character changes, after all the influence of maternal behaviour is a very complex factor. Frances Champagne and his brain trust (Columbia University), studying baby mice raised by negligent and by caring mothers, have discovered similar differences in epigenetic modifications in babies' genes for oestrogens receptors.

So it seems that epigenetic changes can be inherited by the progeny, even if the transmission, in this case, does not follow the germline way. However may drugs, stress, depression and other factors cause epigenetic modifications in germ cells too? After all the effects of every experience and of every psychophysical state reverberate in the whole body: in testicles and in ovaries too. It is very difficult to give an answer to this question since the epigenetic modifications collected during the life are removed during the meiosis.

Recent studies suggest that some epigenetic modifications are probably inheritable: many laboratories have observed that the progeny of stressed out mice has a very low resilience to stress.

Isabelle Mansuy and her brain trust (University of Zurich) have separated the baby mice from the mother for the first two weeks of life and they have observed that later, during the adulthood, the whole progeny suffered from depression. Subsequently, even the offspring of these subjects showed the same symptoms, although they have not been put under stress during the early life. The brain trust has observed that this phenomenon is linked to the modification of the DNA methylation levels in several specific genes in brain and in spermatozoa.

Eric J. Nestler and his colleagues have made a similar experiment in their laboratory. They have put under stress some male mice and they have observed that the offspring suffered from anxiety and insecurety. However if the epigenetic changes are really inheritable, the modifications should be traceable in germ cells too. So the brain trust has fecundated the egg-cells of a normal female subject with the spermatozoa of male stressed out mice and they have observed that the offspring were almost completely healthy, except for some light symptoms of anxiety and insecurity.

However we must consider that probably epigenetic changes can be removed from spermatozoa during the in vitro fecundation process.
These experiments have demonstrated that in general the behaviour of the mothers coupled with stressed up male subjects is different from the character of the mothers coupled with normal mice or fecundated through artificial insemination. So, probably, the depression in the progeny is caused by experiences in the early life rather than by epigenetic modifications inherited through germ cells.

Nevertheless we cannot say that epigenetic modifications collected by the parents cannot be inherited by the progeny through the germline way. We do not have certain evidences yet, however we can see how much all these biomolecular mechanisms are fundamental in our ability to adapt and in our amazing plasticity.

\section{THE CASE OF TRANSFORMING AND REUSING LEARNT CONTENTS: THE COGNITIVE TRANSFERT AS "NOETIC EXAPTATION" AND METAEVOLUTIONARY JUMP}

The cognitive transfert is an excellent example of evolutionary processes (in a wide meaning of the term) that involve noetic sphere. We will focus the perceptive-motor transfert, that is an important side of these processes. It offers us a meaningful example of "noetic exaptation" because it is the opportunistic use of some already existing structures. These cognitive structures can be converted for different aims or in order to use different bodily resources by few, relatively easy and quick modifications. Building a fully new cognitive structure would request a longer time, would imply a much more difficult work, would involve more risks of error. Then it is a question of opportunity and convenience. It is enough to individuate the opportune starting structure and to orienteer the (even simple) transformation in the right direction. Even if it can be a brilliant solution, it is neither so automatic nor warranted in its result.

\section{THE PERCEPTIVE-MOTOR TRANSFERT}

Understanding world and reaching targets by movements are the two sides of interaction between subject and environment: man has a perceptive-motor interaction with his environment.

It is impossible to distinguish these two kinds of processes, as traditional vision has always proposed. The "ballistic" models allow to simplify the systemic nature of this double-sense interaction, disregarding the circular effects between its sides: the perceptive and the motor one. Isolating each one of these two components is misleading because we lose their reciprocal dependence.

A living subject can be "simply organic" as a Para- 
mecium or cognitive or noetic as a man, but in each case it/he searches, orienteers, elects, avoids, transforms, organizes, uses perceptions by action aimed at acting on this function. For example, bodily and ocular movements to explore visual environment or to follow something interesting.

Besides it/he decides, regulates, organizes, leads, stops its/his action by information gained by perception. Multisensorial perceptions are a constant (and constantly used) source of information to act appropriately. "Blind" movements that (for every reason) disregard previous or real-time input are destined to fail.

Always input and output are part of a systemic circle, even beyond the functionalistic vision...

To maximize advantages, to minimize costs and to magnify chances of fitness (not necessarily the extreme success as surviving, but also small partial advantages) man can use previous learning to satisfy new and unexpected requests arising from environment. These requests can be of different kinds:

- Physical. Interactions with physical laws that are not experienced until now. These laws can involve his own body or the surrounding world. The physical factors can be known one by one, but not in certain combinations

- Biological. Interactions with physiological processes of his own organism and/or of other ones, as strength of his own or other's muscular contraction, wideness of articular excursion and so on

- Anthropic. Interactions with cultural and cognitive elements. This involves new explicative apparatuses, new computing algorithms and so on. A sudden intuition can be a good example of cognitive transfert.

"Recycling" old cognitive structures and algorithms offers important advantages:

- We can save a large part of costs and time in building the new contents

- We avoid risks of a quietly new not experienced structure: there is a higher probability that something falls out of control and the subject does not notice eventual incongruities

- Transfert ensures a close relation with the original knowledge and its already established relations with other cognitive contents. This allows an easier memorization and use (both cognitive and concrete use) of the knowledge obtained by transfert.

Understanding and interpreting what we perceive as much as motor skills, even in different ways, are often based on previous knowledge.

We always use this as a source, even if opportunely adapted. An old Latin motto suggests: "Mutatis mutandis". This means: if we appropriately change something, what we can use of the previous knowledge is a valid base. Resembling makes not fully new the new learning and this allows to keep the process and its result under our control.

\section{POSITIVE/NEGATIVE MOTOR TRANSFERT}

Motor learning can be examined in a more analytic way. He has a both adaptive and creative nature.

Learning new skills is an effective way to expand the dominion of the motor competences. The neural functionality and the mental representation can be built "ex nihilo". But, for the already explained reasons, even in different measure and in different ways, most times this result is not obtained "ex nihilo": a previous learning is "recycled" by opportune modifications to reach the new skill. This process is quicker and cheaper than starting from "zero".

Transfert, even in a minimal quantity, happens more or less always. That is to say that each "newly learnt" content always has something "old" inside... This ensures continuity and systemic wholeness to our cognitive evolution.

Cognitive contents and applicative competences are reused.

The changes can be exiguous or conspicuous, but however they are present and they are the margin of originality of new learning. The nature of these transferts is different and first we distinguish positive and negative ones.

- POSITIVE transfert is the happy reusing of previous competences. There is a high grade of affinity between the old action and the new one and this fact makes the transfert easier. However modifications are adequate regarding quality and enough regarding quantity. So the new action is satisfying in reaching the aim and appropriate in its semantic/ communicational aspects.

- In the NEGATIVE transfert the old learning interferes with the new one, due to the fact that it flows into it not appropriately. The affinity between these pushes to a reusing of previously structured contents, but without the necessary modifications. These, even if they happen, are not adequate as quality or not sufficient as quantity. The new learning does not reach an original and specific configuration, so it does not differ enough from the old one, so it is neither effective nor appropriate.

Even if during transfert positive and negative factors can combine, seldom we can speak about a neutral transfert. Always one between these two polarities prevails.

The transfert may be considered a properly named learning, even if "sui generis".

When we teach an action we must activate positive transfert and avoid negative ones.

In order to obtain this it is very important to show relations between the old and the new action, clearly comparing them under different aspects, so similarities and differences are evident.

When we notice a negative transfert we must dissociate the two actions: the old and the new one, trying 
to build a fully new structure for the new action, so that it can escape from the misleading old pattern.

The transfert, disregarding its positive or its negative connotation, can be classified according to the kind of transformation that it requests or products.

Such neuro-cognitive transformation is realized in different ways according to the direction of the jump that is requested for this passage.

So we can have these different kinds of transfert.

\section{BILATERAL TRANSFERT}

The original action that is visually executed by half body (the right or the left one) or it is asymmetrical (it has a chiral structure). By a few attempts, it can be executed also by the corresponding counter-lateral part (or, more generally it is chirally inverted) by opportune transformations of executive algorithm, that is to say by opportune transfert. If we use the same pattern of muscular activation, the action will be obviously chirally inverted. So happened in Leonardo's writing: he wrote by the left hand, that he moved in a mirror-like way. If we aim to obtain the same result by the action of the left hand (compared to the one of the right hand), we must radically change muscular activations. These two ways of realizing bilateral transfert are quietly different: the first way pushes to focus the different parts of body, the second way, on the contrary, pushes to focus the result.

Starting from these different conditions, our brain originates opportune algorithms to convert neuro-muscular activations to obtain the wished aim by the counter-lateral part.

\section{SOMATIC TRANSFERT}

The action that is executed by a part of body can be realized by another part. This part should be a generic one, excluding the counter-lateral one: in this case we would have the bilateral transfert again. For example, if we are able to execute an action by an hand, we can execute it by a foot or by the mouth. If we are able to write (usually we implement this competence by the dominant hand), we can handle the pencil to trace the graphical marks by a foot or by mouth. We can change also the device (a painting brush instead of a pencil) or other parameters. Obviously the subject should focus the shape and the structure of the marks or the kinetic of the action to implement it by the opportune movements.

\section{RE-ARRANGING TRANSFERT}

This is the most studied and showed case in specific literature, insomuch to be identified with "the" trans- fert. A new action should be structured at the neurocognitive level and, aimed at this, it takes advantage from the kinetic similarity with another action that we are able to execute. Usually the new action involves more or less the same parts. We should focus the differences, to obtain the different aim.

\section{DIMENSIONAL TRANSFERT}

A new action can have a similar kinetics but a different dimensional scale. It can be oversized or, on the contrary, undersized. Let us use the example of writing: if we are able to trace signs of half centimeter size by a pen on paper surface, it will not be difficult to use a big paint brush and painting on a wall the same signs two meters wide.

This transformation involves many changes: muscular activations, articular excursions, management of body balance/posture that are quietly different, especially if size difference is conspicuous.

If we want to obtain this kind of transfert it is important to focus on the invariant features of the result of the action (shape, pattern, reciprocal position of the signs), separating them from the other ones (first the dimension, but not strictly only the dimension: pressure on the surface, quickness, use of feedbacks...).

\section{EXECUTIVE TRANSFERT}

The same aim is implemented by an alternative execution. It is not a properly defined transfert, even if the convergence toward the same aim makes the two execution somehow related.

We can take the same example of the writing. If we have not a pen or a pencil available and we have a PC the solution is easy to imagine: we digit the text and we print it. The final aim of the written message is the main point of contact between the two actions. More exactly we focus the hierarchically superior aim, not to write by a pen, but somehow to write the message. This aim can be even more general: to communicate the message. We have no pen and paper, no PC and no printer, but we have a phone: we compose the number and we speak to the addressee.

Comparing this transfert with the re-arranging one we notice that it is the opposite: instead of using the same (or close to same) execution for a different aim, now we use a different execution for the same aim.

\section{METAEVOLUTION FOR OTHER AUTHORS}

During most recent years, many scholars have been interested in metaevolution, even if according to different meanings and perspectives. 
In the matter of this multiplicity of ideas we have chosen a few meaningful examples.

\section{Paras Copra}

Paras Copra speaks about "Metaevolution" or EoE (Evolution of Evolution) as extension of the dominion of evolution toward a systemic dimension. First he restricts the term to the history of life. He agrees with Chaitin in giving centrality to information, disregarding its "natural" or "artificial" nature. On this basis, his main thesis is the impossibility of isolating the linear chain of each species in its evolutionary transformations. Evolution can be understood only if considered as a complex network of feed-backs and feed-forwards between the species and its environment. The subject of evolution is at an upper level: the biome or the whole ecosystem. We cannot preview the course of evolution if we do not consider all aspects. Each single change modifies the other ones. "A change changes another change" and so on, in a systemic network of reciprocal influences. The proposal of a wider systemic horizon for evolutionary events does not seems a very original idea... EoE, in Copra's theory, is the transversal enlargement of evolutionary landscape, instead of involving chronological dimension.

\section{John E. Stewart}

John E. Stewart, in his article "Metaevolution" (Journal of Social and Evolutionary Sciences, Vol 18, Issue 2, 1995, pp. 113-147), similarly to Paras Copra, sees metaevolution in higher level of hierarchy and of network of relations (cooperation etc.) among species in living processes.

The sense of metaevolution that we find in "Meta Evolution" (http://meta-evolution.blogspot.it/, September 7th, 2012) is more interesting. Here the Author proposes "an attempt to generalize the arrow of time: from entropic equalization, to biomorphic reproduction, to cognitive exploration". That is to say that it is possible to individuate a superior level regarding time arrow. Besides there is an interesting distinction among the factors that share the evolutionary feature. In fact this more general level is inclusive of the physical, biological and anthropic ones, defining evolution in a common way.

If we place matter, life and intelligence according to this order we can say that metaevolution can be considered as "incremental abstraction of such conserved cores in higher phases". The conserved core can allow an adaptive environmental interface. In biological systems, the Author individuates the genome and the phenotype, but we could consider also NS and other aspects of organic organization. This makes us think about jumps of expansion of dominion, about emergences each one based on the previous core. In his own words:

"Superficially similar to my interpretation are The Major Transitions in Evolution \& Meta-Systems Transition Theory. From John Stewart's (hopelessly utopian) Evolution's Arrow: "Two attributes that increase as evolution proceeds are the scale of cooperative organization and evolvability through the discovery of effective adaptations." But cooperation as a group selection is a notoriously inefficient mechanism."

In Author's opinion the most important engine of evolution is the conservation of refined/abstract traits, related to complex phenotypes. He writes: “The later, however, is a cost, while core propagation is a benefit (not result) of this trend."

The Author gives a meaningful comparable definition of evolution regarding these three aspects:

- "Entropy growth: equalization \& stabilization of matter $\delta$ energy distribution across space-time for all interacting entities. The maximized fitness here is a continuous recurrence.

- Biological evolution: restoration \& reproduction of internally $\&$ externally differentiated genomes by selective metabolism of their constituents. The fitness is a discontinuous recurrence.

- Cognitive exploration: recognition \& projection of translated correspondence between new inputs $\delta$ known "templates". The fitness is a hierarchically projected model/ environment recurrence."

This three cases have the common aspect of involving the arrow of time, the irreversibility of the processes. It is meaningful, but it is not without risks. The main risk of this vision is the involving of a linear ordinate model, disregarding the reciprocal implications of this different core. For example: information is metabolized not only by cognitive systems, but also by organisms (RNA-DNA, hormones, chemical mediators, enzymes, NS, etc.) and cognitive systems are linked to matterenergy processes, and contemporaneously influenced by them.

\section{Adam Nellis}

Adam Nellis (Towards meta-evolution via embodiment in artificial chemistries, $\mathrm{PhD}$ thesis, University of York, Computer Science Dpt., ID code 3701, 2013) defines metaevolution as "the ability to generate novel ways of generating novelty" (very close to the meaning we attribute to this term) and places it in the field of Artificial Life research, referring to meta-evolutionary algorithms. "Embodiment" is the factor that makes biological and computational systems a unique field of study. The embodiment is the condition, both for biological and for computational systems, to accede to meta-evolutionary possibilities.

Specific aspects of information and its evolutionary transformation are studied in a particular field of research, called "informationalism". Mainly it has developed in technological contests, such as microelectronics and genetic engineering.

The most meaningful features of information are:

Its capability of self-expanding, regarding volume, complexity and speediness

Its recombining capability 
Its distributed flexibility, empowering human capability of elaborating it (information)

\section{Sebastian Seung}

Sebastian Seung (Connectome: How the Brain's Wiring Makes Us Who We Are, Houghton Mifflin Harcout, 2013; Italian translation: Connettoma. La nuova geografia della mente, Codice editore, Marzo 2013) explains why human NS is a metaevolutionary jump: it contains much more information than genome. In our NS we find $7.10^{14}$ connections against $10^{6}$ bases in DNA. Therefore in neurological studies it is more important to study the whole network of connections instead of the single neuron.

\section{Warren Weaver}

Warren Weaver was a scholar with a deeply multidisciplinary thought. He was among the earliest scientists in defining complexity in a clear way (Science and Complexity, in "American Scientist", 1948).

Weaver proposes a taxonomy of three types of dynamic systems: simple (with a few variables, usually from one to four, and typical in traditional physics), with disorganized complexity, with organized complexity.

In its own definition the complexity implies a high number of variables. But there is a difference between the disorganized complexity and the organized one. The difference is the grade of connection among their variables. In the disorganized complexity this grade is very low or close to zero. In the organized one the grade is much higher and makes the system an organic whole.

This can be represented by a mathematical model, but we need a kind of math that is quietly different from the traditional one, and also different from the statistical methods: statistics is more appropriate with disorganized complexity.

Weaver also gave the name to a recent science: molecular biology.

The later fifty years of science history demonstrated he was right and the main problems to be solved were regarding complexity, both disorganized and organized.

Many other related studies must be cited. Here we cite some of these, especially the ones realized during the last half century. Even if these studies are deep and wide, we have not a general definition of complexity yet. We have many meanings: algorithmic (Gregory Chaitin, Andrei Kolgomorov), medical (The self-organization at chaos boundaries by Kauffman), biological (morphogenetic fields by Brian Goodwin), chemical (metaevolution by Manfred Eigen), physical (adaptive complexity by Murray Gell-Mann). Maybe, as Weaver said, that complexity cannot be framed into a unique theory.

The beginning of the mathematical approach to complexity can be placed in mid XX century, in thermodynamic contests, referring to systems that are "far from balance" (Prigogine). Local isles of lowering entropy can be found in a universe that unavoidably increases it. This does not contradict the famous "Second Principle". But the most important aspect is the introduction of irreversibility. In mechanics all processes are perfectly reversible, thermodynamic goes according to arrow of time. Even if J.C. Maxwell proposes a kinetic theory of temperature and pressure, these two disciplines remain different. Ludwig Boltzmann introduces the statistic mechanics by his "Theorem $\mathrm{H}^{\prime}$. Here he says that thermodynamic irreversibility is apparent. It seems that the initial condition cannot be obtained again, but it is only a very improbable status of the system: improbable but not (theoretically) impossible. Final balance, the entropic death of the system is only the ensemble of most probable statuses. Nevertheless creative fluctuation are locally possible.

Systems that are far from balance (low entropy) can have the property of further lowering of this parameter. "Thermodynamics of non-balance" becomes an autonomous chapter at mid XX Century. This is linked to the names of several famous scholars: De Groot, Kirkwood, Katchalsky, Mazur, Lars Onsager (Nobel award in 1968), Ilya Prigogine (Nobel award in 1977).

The main contribution of Onsanger and Prigogine was the mathematical demonstration that small fluctuations (that push the system out of the balance and out of the entropic trend only a little) are quickly re-absorbed. On the contrary, if the system is (or goes) very far from the thermodynamic balance is more stable in its condition. Besides it is very probable that this system can become more and more complex, that is to say that it can evolve in this direction. Prigogine names them "Dissipative Systems", due to its possibility of producing more and more negentropy. Obviously it is possible if it can increase the entropy of a further system. The biosphere of Earth is a wonderful example. This conception has been applied to social sciences, to ecology and so on, with effectiveness.

\section{Ilya Prigogine}

Ilya Prigogine is considered the establisher of the self-organization principle, both in scientific and in philosophical field. In the Eighties this arrived to push scholars to enunciate a sort of "Second Principle of Complexity". In this vision all turns around fluctuations, even if only a small part of them reaches the dissipative level. He calls "Critical Fluctuations" the ones that are capable of pushing the system toward a further lowering of entropy, that is to say a condition of higher stability and higher order. This makes critical fluctuations the evolution engine. Besides they are the base of irreversibility and of possible avoiding of classical determinism. Each critical fluctuation places the system in front of a bifurcation: it can "choose" (it happens in a random and not pre-viewable way) among different possibilities: reverse of fluctuation or magnification of fluctuation according to some forms of order. If system does not come back to entropic trend, stochastic equa- 
tions replace linear ones. We can refer to many examples: the cells by Bérnard (in a liquid, disposed in a wide container and with a small deepness, convective movements happen according to hexagonal packaged cells, close one another, of similar dimension) or the chemical reactions by Belusov-Zhabotinskij (whose balance goes toward and back continuously, with regular times, between two different points, evident thanks to the different colour acquired by the substances). All these phenomena can be found in many kinds of systems, disregarding their grade of complexity or the fact of being physical, chemical or biological. The unique condition is that the system is far from balance. Nevertheless, the similarity between physicalchemical systems and biological or social ones is not so direct and non-conditioned. Many scholars do not agree with Prigogine, but however his work gives us the parameters of a new rationality: the probabilistic one instead of the traditional deterministic one.

After Prigogine further researches suggest that the problem of the relations among complexity, self-organization and entropy cannot be studied only in Thermodynamics.

\section{REFERENCES}

Boncinelli E. A caccia di geni, Di Renzo, Roma, 1986. 2001.

Boncinelli E. I nostri geni. La natura biologica dell'uomo e le frontiere della ricerca, Einaudi, Torino, 1998.

Boncinelli E. Le forme della vita, Einaudi, Torino, 2000.

Boncinelli E, Bottazzini U. La serva padrona. Fascino e potere della matematica, Raffaello Cortina, Milano, 2000.

Boncinelli E. La mente che studia se stessa, prefazione in Joseph LeDoux, Il sé sinaptico. Come il nostro cervello ci fa diventare quelli che siamo, Raffaello Cortina, Milano, 2002.

Boncinelli E. Tempo delle cose, tempo della vita, tempo dell'anima, Laterza, Roma, 2003.

Boncinelli E. L'anima della tecnica, Rizzoli, Milano, 2006.

Boncinelli E. Idee per diventare genetista. Geni, genomi ed evoluzione, Zanichelli, Bologna, 2006.

Boncinelli E. Le forme della vita. L'evoluzione e l'origine dell'uomo (nuova edizione), Einaudi, Torino, 2006.

Boncinelli E, Tonelli C. Dal moscerino all'uomo: una stretta parentela, Sperling e Kupfer. Milano, 2007.

Boncinelli E, Coy G. L'universo e il senso della vita. Un ateo e un credente: due uomini di scienza a confronto, San Paolo, Cinisello Balsamo, 2008.

Boncinelli E. Il fiume e le sue propaggini, introduzione in Richard Dawkins, Il fiume della vita. Che cosa è l'evoluzione, Rizzoli, Milano, 2008.

Boncinelli E. Prefazione in Marcello Orazio Florita, L'intreccio. Neuroscienze, clinica e teoria dei sistemi dinamici complessi, FrancoAngeli, Milano, 2011.

Calude C. Theories of Computational Complexity, Elsevier, 1987.

Chaitin G. Algorithmic Information Theory, Cambridge University Press, 1987.

Chaitin G. Evolution of Mutating Software, EATCS Bulletin 97 (February 2009), pp. 157-164.

Chaitin G. Metaphysics, Metamathematics and Metabiology, APA
Newsletter on Philosophy and Computers 10, No. 1 (Fall 2010), pp. 7\{11. Also in H. Zenil, Randomness Through Computation, World Scientific, 2011.

Coufal NG, et al. L1 Retrotrasposition in Human Neural Progenitor Cells, in "Nature", Vol. 460, pp. 1127-1131, 27 Agosto 2009.

Darwin C. On the Origin of Species, John Murray, 1859.

Dawkins R. The Selfish Gene, Oxford University Press, 1976.

Dawkins R. The Ancestor's Tale, Houghton Mi_in, 2004.

Gage Fred H, Muotri AR. L'impronta dell'identità, in Le Scienze $n$. 525, Maggio2012, pp. 50-55 (jumper genes and trasposons).

Haeckel E. Art Forms from the Ocean, Prestel, 2009.

Haeckel E. Art Forms in Nature, Prestel, 2010.

Kelly K. Out of Control. La nuova biologia delle macchine, dei sistemi sociali e del mondo dell'economia, Apogeo, Milano, 1996, original ed.: Addison-Westley Publishing Company, 1994.

de La Mettrie J.O., Man a Machine, Open Court, 1912.

Nestler EJ. Il codice epigenetico della mente, "Le Scienze" n. 522, Febbraio 2012.

Pievani T, Varchetta G. Il management dell'unicità, Guerini, Milano, 1989.

Pievani T. Homo sapiens e altre catastrofi, Meltemi, Roma, 2002.

Pievani T. La teoria dell'evoluzione. Attualità di una rivoluzione scientifica, Il Mulino, Bologna, 2006.

Pievani T. La vita inaspettata. Il fascino di un'evoluzione che non ci aveva previsto, Raffaello Cortina Editore, Milano, 2011.

Pievani T. Introduzione a Darwin, Laterza, Roma-Bari, 2012.

Prigogine I. La fine delle certezze, Bollati Boringhieri, Torino, 1997.

Seung S. Connettoma. La nuova geografia della mente, Codice editore, Marzo 2013.

Singer T, et al. LINE-1 Retrotrasposons: Mediators of Somatic Variations in Neuronal Genomes?, in "Trends in Neurosciences ", Vol. 33, n. 8, August 2010.

Smith JM, Szathmáry E. The Major Transitions in Evolution, Oxford University Press, 1997.

Smith JM, Szathmáry E. The Origins of Life, Oxford University Press, 1999.

Tanga M, Ghelli F. "Darwin tra bio e bit - Darwin between bio and bit", in "Atti dell'Accademia dei Fisiocritici", Siena, 2009.

\section{WEBOGRAPHY}

Aaronson S., http://www.scottaaronson.com/writings/big numbers.html, For a magnificent visual depiction of the exuberant creativity of Nature, see Ernst Haeckel's splendid books Art Forms from the Ocean and Art Forms in Nature

Chaitin G., http://www.cs.auckland.ac.nz/CDMTCS//research reports/39lgreg.pdf

WWw.ncbi.nlm.nih.gov/pmc/articles/PMC2916067/?tool=pu bmed

http://piopas.xoom.it/piopas/prigogine/prigoginel8.htm http://paraschopra.com/articles/metaevolution/index.php www.elencoforum.com/it/tag/meta/evoluzione WWW.tesionline.it

www.aelfwine.info

http://www.aelfwine.info/wp-content/uploads/2012/02/ Fabio-Alvino-Elaborato-Teorico-_-Ecologia-della-Mente.pdf http://www.sciencedirect.com/science/article/pii/106173619 5900330

http://meta-evolution.blogspot.it/ 